\title{
Geleitwort der Bundesministerin der Justiz und für Verbraucherschutz
}

Vor 100 Jahren wurde mit der Verabschiedung des Gesetzes über die Errichtung eines Reichsfinanzhofes und über die Reichsaufsicht für Zölle und Steuern vom 26. Juli 1918 das Fundament für den Aufbau einer einheitlichen und eigenständigen Steuergerichtsbarkeit in Deutschland gelegt. Es ist aus heutiger Sicht bezeichnend, dass die Initiative für dieses Gesetz, das in enger Verbindung mit dem am gleichen Tag verabschiedeten neuen Umsatzsteuergesetz stand, vom Reichstag als dem einzigen demokratisch legitimierten Verfassungsorgan des Kaiserreichs ausging. Der Reichstag war nur bereit, die mit den neu eingeführten Reichssteuern verbundenen Belastungen für die Bevölkerung zu akzeptieren, wenn eine gerechte Verteilung der Steuerlast sowie ein wirksamer und einheitlicher Rechtsschutz in Steuersachen durch die Errichtung eines obersten Steuergerichts auf Reichsebene gewährleistet würden. Dieser Vorgang ist ein anschauliches Beispiel dafür, wie sehr die Akzeptanz und Stabilität einer Steuerrechtsordnung auf wirksame Rechtsschutzinstitutionen angewiesen ist.

Heutzutage erscheint es beinahe selbstverständlich, dass Bürgerinnen und Bürger bei Steuerstreitigkeiten mit den Finanzbehörden Rechtsschutz vor einer eigenständigen Fachgerichtsbarkeit suchen können, die in voller Unabhängigkeit von der Finanzverwaltung steht. Das vorliegende Werk verdeutlicht, indem es in seinem ersten Teil den Blick auf die Geschichte der Steuerrechtsprechung in den letzten 100 Jahren richtet, dass unser heutiger Rechtsschutzstandard das Ergebnis einer langen und auch mühevollen Entwicklung ist, die nicht geradlinig verlief. Tatsächlich waren beispielsweise die im Jahr 1921 als Vorinstanz des Reichsfinanzhofes gebildeten Finanzgerichte noch eng mit der Finanzverwaltung verquickt, da sie den jeweiligen Landesfinanzämtern angegliedert waren. Die noch nicht vollständig vollzogene Trennung zwischen Exekutive und Judikative kam auch in den Bestimmungen der Reichsabgabenordnung von 1919 zum Ausdruck. Denn diese enthielt neben Regelungen über die neue Finanzverwaltung auch solche über die Organisation der Steuergerichte. Während man in der Weimarer Republik bemüht war, den Reichsfinanzhof und die Finanzgerichte in ihrer Unabhängigkeit zu stärken, ging die Unabhängigkeit der Steuerrechtsprechung in der Zeit des Nationalsozialismus verloren. Der Reichsfinanzhof erließ in dieser Zeit in Steuerangelegenheiten jüdischer Mitbürgerinnen und Mitbürger Unrechtsurteile, die bis heute einen dunklen Schatten auf seine Geschichte werfen. Erst unter den Bedingungen der freiheitlichen Ordnung des Grundgesetzes gelang ein stetiger Wiederaufbau der Finanzgerichtsbarkeit. Dieser führte im Jahr 1950 zur Errichtung des Bundesfinanzhofes als erstem der in Artikel 95 Absatz 1 des Grundgesetzes genannten obersten Gerichtshöfe des Bundes. Seinen Abschluss fand er mit Inkrafttreten der Finanzgerichtsordnung und der Errichtung der von den Finanzbehörden getrennten und unabhängigen Finanzgerichte zum 1. Januar 1966. Mit dem Übergang der Ressortzuständigkeit für den Bundesfinanzhof vom Bundesfinanzministerium auf das Bundesministerium der Justiz im Jahr 1969 wurde auch für dieses Gericht die klare Trennung von Steuerverwaltung einerseits und Steuerrechtsprechung andererseits endgültig vollzogen. 
Die Finanzrechtsprechung hat in der Bundesrepublik die geltende Steuerrechtsordnung maßgeblich geprägt und sich als wichtiger Garant des Rechtsstaates erwiesen. Sie hat sich als spezialisierte und eigenständige Fachgerichtsbarkeit auch angesichts des in den letzten 100 Jahren deutlich komplexer gewordenen Steuerrechts voll bewährt. Wie vielfältig die Bezüge des Steuerrechts und der Steuerrechtsprechung sind, zeigen die Beiträge im zweiten bis fünften Teil dieses Buches. Die Vielfalt der Themen veranschaulicht zugleich die hohen fachlichen Ansprüche, die an Richterinnen und Richter der Finanzgerichtsbarkeit gestellt werden. Dabei ist besonders hervorzuheben, dass sich die Verfasserinnen und Verfasser der Beiträge nicht darauf beschränken, sich des Erreichten zu vergewissern, sondern den Blick auf die noch zu bewältigenden Aufgaben im Bereich der Steuerrechtsprechung und des materiellen Steuerrechts richten.

Diese Aufgaben werden in der Zukunft sicher nicht leichter. Der rasante technische Fortschritt, insbesondere die alle Lebensbereiche erfassende Digitalisierung, bedeutet auch für die Finanzgerichtsbarkeit neue Herausforderungen. Neue finanzbehördliche Eingriffs- und Ermittlungsinstrumente sowie ein erweiterter grenzüberschreitender Datenaustausch führen zu neuen Herausforderungen beim Ausgleich von Effektivität des Steuervollzuges und den Grundrechten der Steuerpflichtigen. Zugleich ist die Finanzgerichtsbarkeit selbst unmittelbar vom technischen Fortschritt betroffen: In den nächsten Jahren wird insbesondere die Umstellung auf elektronische Arbeitsgrundlagen voranschreiten und in der Justiz die Arbeitsweise der Gerichte umfassend verändern. Ich bin mir sicher, dass die Finanzgerichtsbarkeit gut gerüstet und hinreichend flexibel ist, um auch die künftigen Herausforderungen zu meistern.

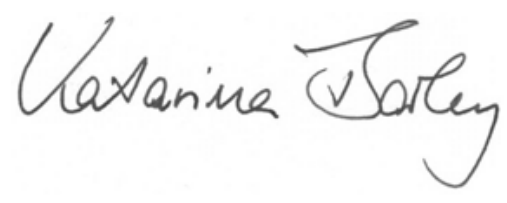

Dr. Katarina Barley

Bundesministerin der Justiz und für Verbraucherschutz 